\title{
Rice in Dravidian
}

\author{
Franklin Southworth
}

Received: 17 October 2011 / Accepted: 8 December 2011 /Published online: 18 January 2012

(C) Springer Science+Business Media, LLC 2012

\begin{abstract}
The Dravidian languages, now spoken mainly in peninsular India, form one of two main branches of the Zagrosian language family, whose other main branch consists of Elamitic and Brahui. Proto-Dravidian, the oldest reconstructible form of Dravidian, shows a society whose economy is based mainly on herding. While the speakers of Proto-Dravidian had some agricultural knowledge, they do not appear to have brought cereals with them when they moved from western Iran to the borderlands of South Asia in the fourth millennium BCE. Linguistic evidence shows that they had contact with Indo-Iranian speakers, and some groups of Dravidian speakers entered the Indus Valley before or during the period of the Harappan civilization. Dravidianspeaking groups played a significant role in herding and agriculture during that period and later, and may have been the first to cultivate rice on a large scale in the Indus Valley.
\end{abstract}

Keywords Dravidian · Elamite · Indo-Aryan · South Asia · Iran $\cdot$ Central Asia $\cdot$ Millets

\section{Introduction}

The locations of the modern Dravidian languages are shown in Fig. 1. As indicated in Fig. 2, Dravidian as a whole is a branch of the Zagrosian language family, named for the Zagros mountains in western Iran. (The relationship between Dravidian and Elamite was adumbrated in McAlpin 1981, and has not yet been universally accepted; however, several recent and forthcoming publications present further evidence of its viability: see McAlpin 2003, 2012,

F. Southworth $(\triangle)$

South Asian Linguistics (Emeritus), University of Pennsylvania, 820 Williams Hall/6305,

Philadelphia 19104, PA, USA

e-mail: frank.southworth@gmail.com unpublished, and Southworth and McAlpin 2012, unpublished.) Dravidian is divided into two main branches (see Fig. 2): North Dravidian, consisting of two languages, Kurux and Malto, and Peninsular Dravidian. Brahui, formerly considered a Dravidian language, has now been shown to be more closely related to Elamitic (see McAlpin 2012, unpublished). Peninsular Dravidian consists of four subgroups, shown in Fig. 1, whose relationships have yet to be established. ${ }^{1}$ There is strong linguistic evidence for a former Dravidian-speaking presence in western India, in the area now occupied by the Indo-Aryan languages MarathiKonkani, Gujarati, and possibly Sindhi (in Sindh, Pakistan), as indicated in Fig. 1 (Southworth 2005:317-18). This evidence includes lexical and structural borrowings from Dravidian into the Indo-Aryan languages of the area (see Fig. 3 below), as well as Dravidian place-name suffixes in Maharashtra, Gujarat and Sindh (Pakistan). Dravidian-derived names of rivers are found in the Marathi-speaking region (Nampoothiry 1987, cited in Witzel 1999). While it is clear that the Dravidian presence in this area predates the arrival of IndoAryan languages, this evidence does not make it possible to establish the chronology of this presence, other than to show that the Dravidian linguistic influence in this area can probably be ascribed exclusively to Proto-Peninsular Dravidian, rather than to North Dravidian or ProtoDravidian. The following section provides some chronological estimates. The remainder of the paper deals with the prehistory of the Dravidian languages and their relationship to rice, as far as can be determined by linguistic evidence.

\footnotetext{
${ }^{1}$ Existing subgroupings of Dravidian (see, e.g., Krishnamurti 2003:492-501; Southworth 2006) are unsatisfactory, as they fail to deal with the question of diffusion (both structural and lexical) among the subgroups of Peninsular Dravidian. The present locations of these languages appear to be the result of several millennia of intermittent contact; even assuming that the history of this contact can be unraveled, it is unlikely that it could be represented by a simple tree diagram.
} 


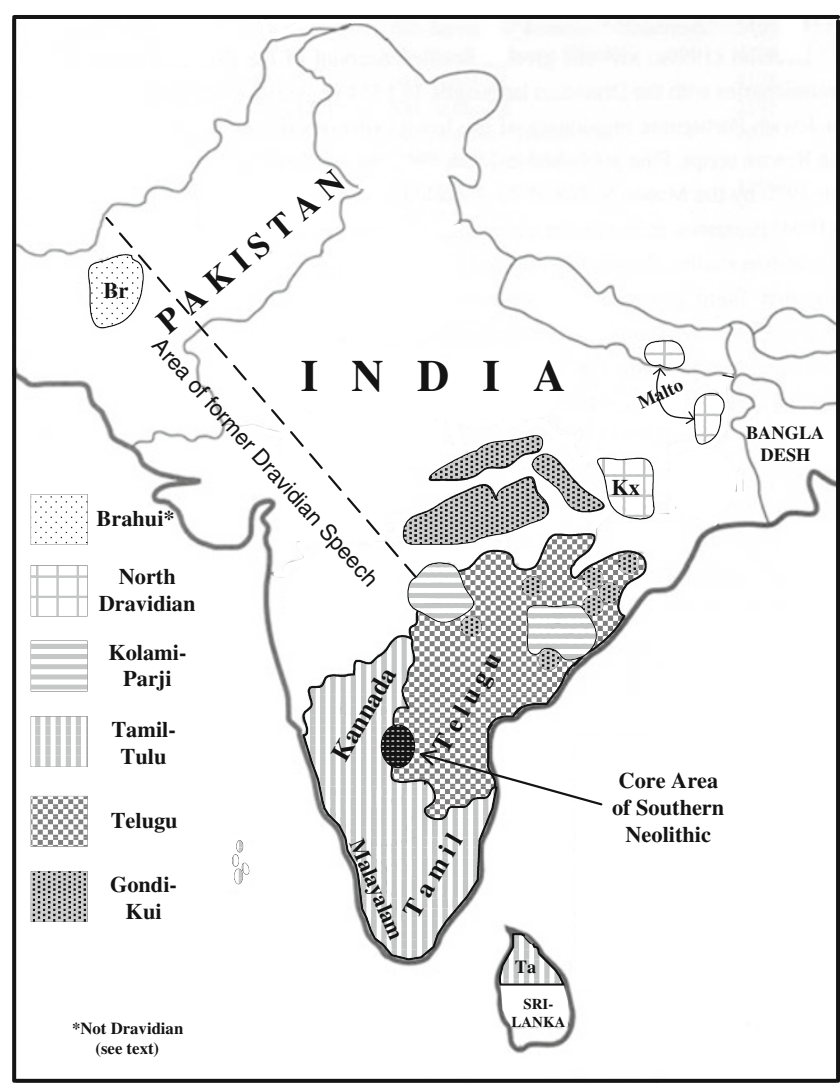

Fig. 1 Locations of modern Dravidian languages.

\section{Results}

In addition to the evidence mentioned above, linguistic evidence for Dravidian prehistory includes (1) the reconstructed vocabulary of Proto-Dravidian, (2) the names of

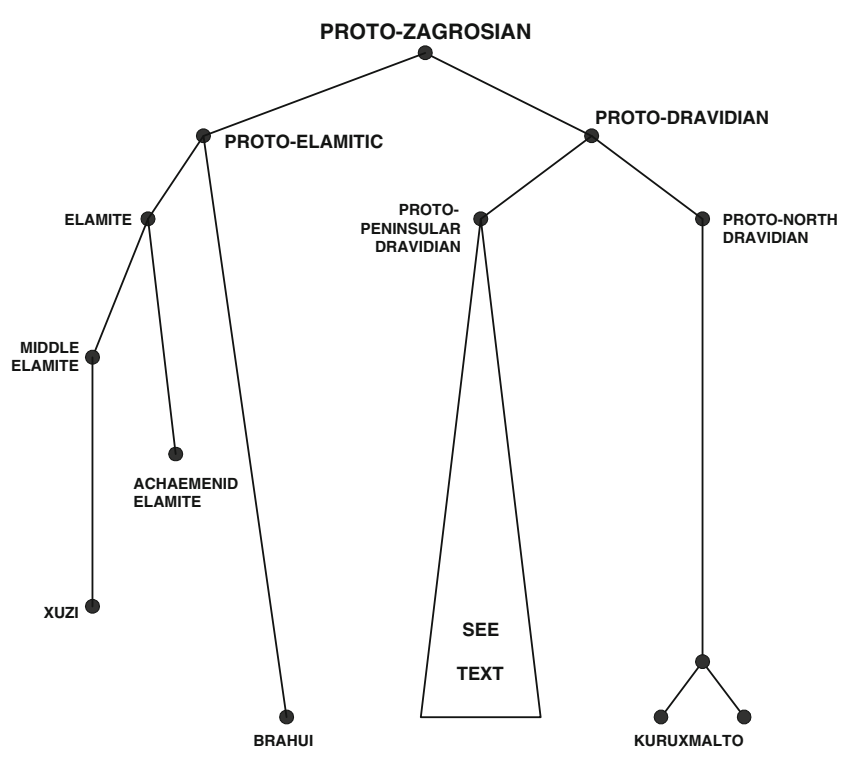

Fig. 2 Proto-Zagrosian family tree.

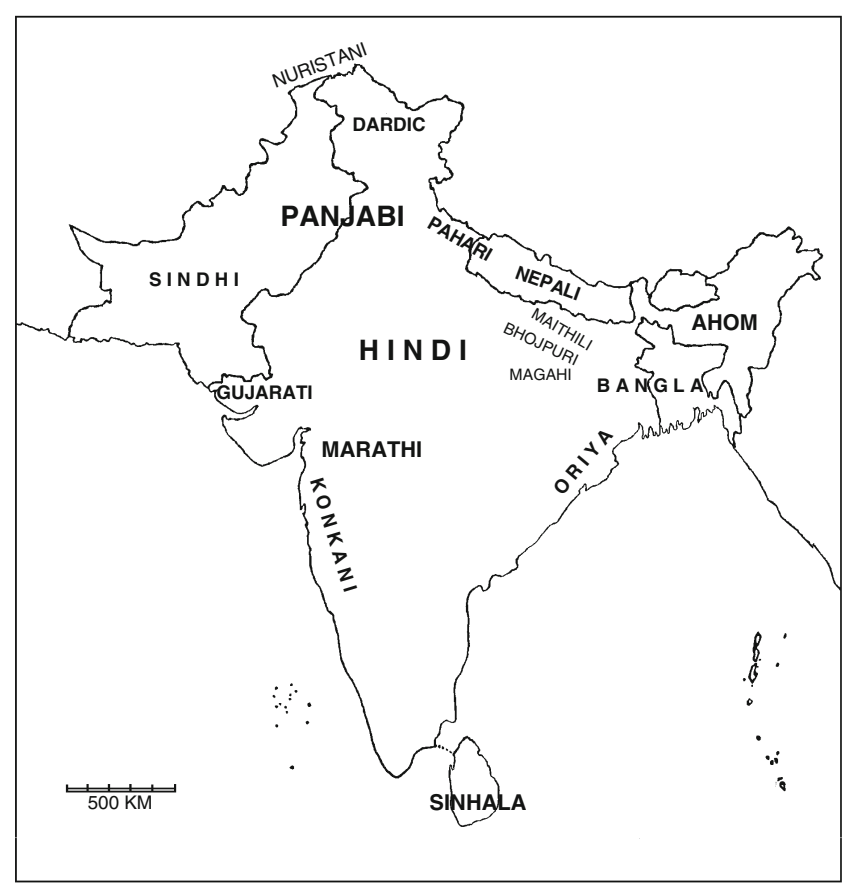

Fig. 3 Locations of modern Indo-Aryan languages.

crop plants reconstructed for the period of the Southern Neolithic Agricultural Complex, and (3) loanwords in Old Indo-Aryan (Vedic, Classical and Epic Sanskrit) showing contact between early Indo-Aryan and Dravidian languages.

\section{Proto-Dravidian}

The reconstructed vocabulary includes terms related to herding, with words for sheep, goat, cattle inherited from Proto-Zagrosian: PZ *aš "cow"2; Achaemenid Elamite aš "cow, herd", Proto-Dravidian * $\mathbf{a}(\mathbf{y})$ "cow" Dravidian Etymological Dictionary (DEDR) 334, Brahui xar-ās "bull" DEDR 1123 (compounded with xar "male animal?"); Proto-Zagrosian *hẹțu "sheep, goat", Elamite hidu "sheep, goat", Brahui hēṭ "she-goat", Proto-Dravidian *yāțu "sheep, goat" DEDR 5152, along with verbs referring to driving and grazing animals, words for herd, flock, shepherd, and several words which mean both house/dwelling and animal stall. Though there are agricultural terms including words for winnowing, churning, reaping, and grinding grain, along with several words meaning "grain/seed", "chaff" and "husk", and possibly a word for the plough, no words for specific cereals are reconstructible (Southworth 2009; Southworth and McAlpin 2012, unpublished).

\footnotetext{
${ }^{2}$ In historical linguistics, reconstructed (or otherwise unattested) forms are preceded by $*$, to distinguish them from forms which have been attested in speech or writing.
} 
The southern neolithic archaeological complex

The first dateable archaeological assemblage which can be positively connected with Dravidian is the Southern Neolithic Archaeological Complex, which is known from about the middle of the third millennium BCE. Apart from the close relationship between the list of crops identified archaeobotanically in Phases II and III of the Southern Neolithic (resp. 2300-1800 and 1800-1200 BCE) and the names of crops reconstructible within Peninsular Dravidian (Southworth 2009), the Southern Neolithic lies totally within the area now occupied by the extant Dravidian languages, and the core area of the Southern Neolithic lies astride the boundary between two of the major subgroups of Peninsular Dravidian. Thus, even though there may well have been other languages spoken in the area before Dravidian speakers entered it, there can be little doubt that the dominant languages of the Southern Neolithic were Dravidian.

Even for this stage of Dravidian, possibly a millennium younger than Proto-Dravidian, it is difficult to reconstruct the names of specific cereals. Apart from rice (see "Rice in Dravidian" section below), three words for cereals have cognates in all four subgroups of Peninsular Dravidian. The first of these, which can be reconstructed as ProtoPeninsular Dravidian *conna-I DEDR 2896, possibly derived from *cō!- (of unknown meaning) + nel "paddy, growing rice" DEDR $3753(? \leftarrow$ ñāl- "earth, field" DEDR 2913), is glossed as Sorghum vulgare (or equivalent terms) in at least one language in each subgroup; on the other hand, it is glossed as "maize" in languages of three subgroups, and in one language (Kannada of the Tamil-Tulu subgroup) is glossed only as a "generic name for several species of millet", and in another (Kui, Gondi-Kui subgroup) simply as "millet". The second word, *kot-V DEDR 2163, is glossed as Setaria italica or the equivalent in languages of three of the four subgroups, but in the fourth subgroup as "Panicum miliare", "Eleusine coracana", "a grain", and "millet". It is possibly connected with *korr- "food" DEDR 2171. A third word, *ār-V-k-/*ar-V-k-, has similar multiple glosses, and is perhaps derived from *ar-V-k(k)- DEDR 212 "to cut; to harvest". In all these cases, the most cautious reconstruction would be "(a) millet" (assuming, in the case of the first item, *conna-l, that the gloss "maize" was a local term for "millet", as very little maize is grown in India). ${ }^{3}$

\section{Dravidian loanwords in Old Indo-Aryan}

The Old Indo-Aryan ritual texts are believed to commence from about $1750 \mathrm{BCE}$, starting with the Rigveda, the oldest

\footnotetext{
3 Thus, Southworth's (2009) reconstructions of 'sorghum' for *conna-l, and "Setaria italica" for *kot-V were overoptimistic at best. See further discussion in "Methods" section below.
}

of the four Vedas ${ }^{4}$ of Hinduism. The Rigvedic period ended about $1200 \mathrm{BCE}$, followed by the late Vedic period (see Witzel 1999) and the periods of Epic and Classical Sanskrit, which continued into the Christian Era though Sanskrit was no longer anyone's mother tongue. The term "Old IndoAryan" refers to the whole of Sansrit literature, from Vedic through Classical. Dravidian loanwords in early Old IndoAryan have been seen by many scholars as evidence of a Dravidian presence in northern India during that period. Although the earliest attested Dravidian loanwords do not appear in the Rigvedic texts until after 1500 BCE (Witzel 1999), it has been recently pointed out (Southworth and McAlpin 2012, unpublished) that cognate forms of these words are found in the Nuristani and Dardic languages (see Fig. 3); these are modern Indo-Aryan languages which are believed to have had very little contact with the rest of IndoAryan - until very recent times - since about $1900 \mathrm{BCE}$ in the case of Nuristani, and about 1600 BCE in the case of Dardic (Blažek and Hegedus 2010). Thus, it is probable that Dravidian loanwords with cognates in Nuristani languages were borrowed into Indo-Aryan before the Rigvedic period; those with only Dardic language cognates may have been contemporaneous with the Rigveda or earlier.

Words of presumed Dravidian origin found in (middle and late) Rigvedic texts which have significant representation in Nuristani/Dardic languages include:

1. phala "fruit" [3/7]: Proto-Dravidian *paz- "to ripen", *paz-a "old", Tamil pazam "ripe fruit" DEDR 4004

2. pinda "lump" [0/13]: Proto-Dravidian *pizi , past *pizi-nt "squeeze", *pint ț-V(<-*piżi-nt-V) "that which is squeezed" DEDR 4183;

3. danda "stick, club" [4/8]: Proto-Peninsular Dravidian *tan t-V "stem, stalk (of plant), trunk (of tree)" DEDR 3048,3056

4. kunda "bowl, waterpot; hole, pit" [2/6]: ProtoDravidian *qun d -V "depth, cavity, pit" DEDR 1669 $\leftarrow<-$ *quz-nt-V "hollowed out" DEDR 1818

5. khala "threshing floor" [1/8]: Proto-Dravidian *qal "field" DEDR $1376 \leftarrow$ Proto-Zagrosian *qal "field", cf. Proto-Elamite *xal, Elamite hal "land"

6. godhūma "wheat" [4/17]: Proto-Dravidian *kōlum "grain" DEDR $1906 \leftarrow$ Proto-Zagrosian *kōlum “grain”, cf. Proto-Elamite *ǩōlum, Elamite šulum "standing grain", Brahui xōlum "wheat", probably borrowed into Indo-Aryan as *kōlum and subsequently modified folk-etymologically (see Witzel 1999 for a different view);

\footnotetext{
$\overline{{ }^{4} \text { OIA veda }=}$ "knowledge", cf. English wit, German wissen "to know".
} 
7. gardabha "donkey" [1/8]: Proto-Peninsular Dravidian *kaz-ut-ay "donkey" $\longleftarrow$ "wild ass" (Parpola 2011); note also Vedic khara, Avestan xara "donkey" (Witzel 1999: 54 suggests a possible Central Asian source for all these words).

In addition to the above items (which are only the most obvious of a larger number of cases), a number of other words show the same distribution in modern IndoAryan-i.e., a significant representation in Nuristani and Dardic languages - even though they are attested later in the literary record of Old Indo-Aryan; for example:

8. èda "a kind of sheep" [0/8], a late Vedic word: PD *yāț u "sheep, goat" DEDR $5152 \leftarrow$ Proto-Zagrosian "hēțu "sheep, goat", cf. Elamite hidu "sheep, goat", Brahui hêt "she-goat"

9. khura "hoof" [1/15], also late Vedic: Proto-Peninsular Dravidian *kur-V-c- "hoof; deer" DEDR 1770, 1785

10. ganda "joint of plant" (a late word) [1/4]: ProtoPeninsular Dravidian *kan t $\mathbf{~ - V ~ " j o i n t ~ o f ~ f i n g e r , ~ s u g - ~}$ arcane, etc.” DEDR 1946.

Numbers in brackets indicate the number of Nuristani/ Dardic languages with cognates (Turner (1966) lists six Nuristani languages and 19 Dardic languages). DEDR numbers refer to entries in Burrow and Emeneau (1984). $\mathbf{V}=$ an indeterminate vowel. The symbol $\leftarrow=$ "comes from" or "is derived from". See Southworth (2012, unpublished) for additional details on the above etymologies.

\section{Rice in Dravidian}

To begin the discussion of words for rice in Dravidian, it should be pointed out that in rice areas of South Asia it is common to find different words used for the various forms which rice takes in the process of coming from field to table. For example, in Tamil (Dravidian) and Marathi (Indo-Aryan) the following distinctions are made:

\begin{tabular}{lll}
\hline & Tamil & Marathi \\
Rice plant in the field ("paddy") & nellu & dhān \\
Rice after threshing/in storage & arici & tāndu! \\
Cooked rice & cōru (Brahman sādam) & bhāt \\
\hline
\end{tabular}

The words "rice" and "paddy" occur in 249 entries in the revised edition of the DEDR (Burrow and Emeneau 1984), which amounts to over $4 \%$ of the 5,575 entries in the entire dictionary. While some of these entries only have cognates in two or three languages (often belonging to the same subgroup), and others mention rice only incidentally (e.g., the entry for PD *attt-am "upper story" includes a derivative in Tulu meaning "loft for storing rice"), this number still indicates the importance of rice in South Indian culture. For the present purpose, I will discuss a few important semantically related words, starting with the following:

1. The word *vari-(n)ci (with variants *vari, *varici, *varinci) "rice, paddy" DEDR 5265 can be reconstructed for Proto-Peninsular Dravidian, as cognate forms are found in languages of all four subgroups; it is not reconstructible to North Dravidian. It is the source of the word for "paddy"-i.e., rice in the field or after harvesting and threshing, either husked or unhusked, but not yet cooked - in most of the modern Peninsular Dravidian languages. This word may be connected to the Elamite bar "seed"- - though there is some doubt, as the phonetic correspondences are not regular. A related form, *ari-ci/ki, with variants ari, arici, akki, arki (the last two $\leftarrow *$ ariki) DEDR 215, refers to husked rice or other husked grains, and is found only in the languages of the Tamil-Tulu subgroup of Proto-Peninsular Dravidian. It also has the meaning "seed", as in Tamil êlav-arici "cardamom seed", Kannada êl-akki. Though *vari-(n)ci and *ari-ci/ki appear to be related, the phonological correspondence is not expected (initial ${ }^{*} \mathbf{v}$ - is not normally lost in these languages).

2. Proto-Peninsular Dravidian *tant-u!! "beat-en" refers to husked grain, i.e., grain that has been beaten to remove the husk-see *tanțtant- "to beat (as a drum), to kick" DEDR 3053, and *u!- "to be" DEDR 697.

The first of these forms, *vari-(n)ci, bears comparison with Old Indo-Aryan vrīhi "rice", a word first attested in the Atharvaveda (ca. 1200 BCE). This word has apparent cognates in two Nuristani languages (Kati wrić, ŕíc, and Prasun wuzī, both meaning "barley") and in five different dialects of the Dardic language Shina: Gilgiti bĩŭ, Kohis-

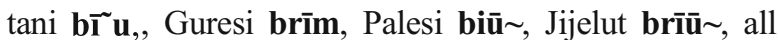
meaning "rice". The only other modern cognates in Indo-Aryan are Sinhala viya "growing rice" and Maldivian vi "paddy, rice-seed". The Kati form wric "barley" is very close phonologically to the PPD variant *varici, though not semantically, since it refers to barley rather than rice. The Shina forms all show nasalization, possibly reflecting the variant *varinci, which seems to be connected with Old Iranian *brinj, Farsi birinj "rice" (as noted by Witzel 1999). The Skt. vrīhi, on the other hand, has -h- which is not the normal equivalent of Dravidian -c-, suggesting that there may have been contamination from another source, as yet unknown. ${ }^{6}$

\footnotetext{
${ }^{5}$ Maldivian is an offshoot of Sinhala in the Maldive Islands.

${ }^{6}$ It is not beyond the bounds of possibility that Dravidian *varici is also the source of Vedic bīja 'seed' [3/8] (also found in Iranian, see Witzel 1999:55), possibly by a different route: similar forms of both are found in dialects of Shina, e.g., bi "seed", bĩ $\mathbf{u}$, "rice".
} 
The second word above, *tant-ul!a, may be compared with OIA tandula, also first attested in the Atharvaveda, which is glossed as "grain, esp. rice, after threshing and winnowing". This word has cognates in ten Dardic languages, with meanings including "rice", "husked rice", "boiled rice", and "rice in the fields"; there are also cognates in Gujarati, Marathi, Oriya, and Old Bangla with the meaning "husked rice". The appearance of these two words in the same period of time may be interpreted as a clue to the existence of the sort of rice culture found in modern Marathi and Tamil, with separate words for the different stages of rice preparation. A third word, Old Indo-Aryan bhakta "food, meal" ( $\leftarrow$ bhaj- "to eat, enjoy", not of Dravidian origin), whose reflexes in most modern Indo-Aryan languages refer to cooked rice, would have completed the pattern shown above. ${ }^{7}$

The absence of cognates of vrīhi and tandula in most of the modern Indo-Aryan languages calls for comment. Since in both cases, cognates are found in the northernmost and southernmost languages, these two words probably once occurred in all or most of modern Indo-Aryan. However, a later word, *cāmala/*cāvala (attested first in Middle Indo-Aryan, e.g., Prakrit cāulā) replaced both OIA vrīhi and tandula in the majority of languages, leaving remnants of the two older words only in peripheral areas: as noted above, reflexes of vrīhi occur only in Nuristani, Dardic, Sinhala, and Maldivian, while reflexes of tandula are found only in Kashmiri (Dardic), Gujarati, Marathi, Oriya, Old Bangla, and Sinhala. The reflexes of tan d ula in Kashmiri, Old Bangla, and Sinhala seem to be combinations of tandula and *āmala/*āvala- e.g., Old Bangla tāula-indicating that the two words probably coexisted in those languages for a time. The Dravidian source of *cāmala/*āvala, is *caval "mortar; to pestle; rice husked by pestling" DEDR 2391, which seems also to be a late word in Dravidian, as it occurs in only two subgroups of Proto-Peninsular Dravidian. Thus, the replacement of the older Dravidian words by this later Dravidian word may have taken place in the late centuries $\mathrm{BCE}$ or later.

\section{Discussion}

The reconstructed vocabulary of Proto-Dravidian depicts a society whose main source of food is animals and their products. Though the speakers of Proto-Dravidian had some

\footnotetext{
${ }^{7}$ The chronology here is not certain. The word appears to have referred to "food" or "a meal" in Vedic and Classical Sanskrit. Middle IndoAryan has Prakrit bhatta "food, rice", and the meaning 'boiled rice' is first found in a late Sanskrit text, probably early CE.
}

knowledge of agriculture, the absence of reconstructible names for cereals strongly suggests that they were not sedentary farmers at this stage - rather, they were probably herders of sheep and cattle, supplementing their diet with grains and other agricultural products through gathering, trade, and occasional periods of sedentism. The first association of Dravidian speakers with a specific cereal is signaled by the occurrence of the word gōdhūma "wheat" in Vedic Sanskrit, a word derived from a Proto-Zagrosian word meaning "stand of grain". This word, along with other Dravidian-derived words relevant to agriculture (words for "fruit" and "field, threshing ground", "joint of plant") and animals (words for "sheep", "ass", "hoof") suggests a significant role for Dravidian speakers in Indus Valley agriculture. As the distribution of these words in modern Indo-Aryan languages - with cognate forms in Dardic and/or Nuristani languages - is similar to that of inherited words like Old Indo-Aryan bhrātro "brother" (4 Nuristani, 16 Dardic cognates) or mātr "mother" (four Dardic cognates), it is reasonable to assume that the initial contact between Indo-Aryan and Dravidian speakers took place outside of the Indus Valley, in parts of Iran, Afghanistan, or Turkmenistan, probably at a time when Dravidian speakers were involved in wheat cultivation. Chronologically, this might have been anywhere "from about 3500 BC onwards", in Bellwood's words (2005:334, see also Bellwood 2009). The presence of cognates of some of these loans in Iranian languages suggests that both Indo-Aryan and Iranian-speaking groups may have been involved in early interactions with Dravidian speakers.

By the mid-third millennium BCE, Dravidian had become the dominant language of the Southern Neolithic; the Dravidian languages had split into North Dravidian and Peninsular Dravidian, and the latter was further divided into four subgroups. The Southern Neolithic was ".... a system that combined animal husbandry-including the wellknown cattle pens (Allchin 1963) - with a new package of crops, of which the staples were legumes and millets, a description applicable to the diet of most South Indians today" (Southworth and McAlpin 2012, unpublished). Its main cereal crops were two millets, bristley foxtail (Setaria verticillata) and browntop (Brachiaria ramosa), whose names were either taken from some unknown language(s) or derived from existing Dravidian words such as *korr"food" DEDR 2171. Since South India is not a suitable climate for wheat cultivation, the old word for "wheat" was no longer even a memory, surviving only as Tamil kūlam, a generic term for "grain", and a few related words in Gondi-Kui (DEDR 1906). When Dravidian speakers today refer to wheat, they use a form borrowed from Sanskrit godhūma, such as Tamil gōdume.

Contrary to Southworth's claim (2009) that the language of the Southern Neolithic was a form of "late ProtoDravidian" (equivalent to what is now being called "Peninsular 
Dravidian"), it now appears that the Southern Neolithic involved a coming together of various subgroups of ProtoPeninsular Dravidian which had already separated some time previously, had been in intermittent contact over a long period in the interim as each branch developed its own unique crop package, and ultimately pooled their resources to create the collection of crops identified in the Southern Neolithic.

Regarding rice: the Proto-Peninsular Dravidian word *vari-(n)ci, which probably originally had the meaning "seed, grain", appears first as a word for "barley" in two Nuristani languages. The contact that produced the Nuristani words is perhaps dateable to the same period as that of the word for "wheat": any time from about 3500 BCE onwards. Lacking evidence to the contrary, it seems reasonable to assume that Dravidian-speaking farmers became part of the population of the Indus Valley from about that time. That they retained that role for a long period of time is shown by the appearance of the OIA words vrīhi "paddy" and tandula "threshed (husked/unhusked) rice" in about $1200 \mathrm{BCE}$, and by the later replacement of these words by another Dravidian loanword, *cāmala/*cāvala, a millennium or so later. Additional evidence may come from other names of cereals: for example, Dravidian *connal "millet" is the probable source of the late Sanskrit yavanāla (reshaped under the influence of OIA yava "barley"), the source of modern Indo-Aryan words for "sorghum" such as Marathi jondha! $\mathbf{a}$.

\section{Methods}

For the methods of historical-comparative linguistics in general, including the methods of reconstruction, see Bradley (this volume), "Methods" section; for additional detail see Southworth 2005, Ch. 1. A short discussion of semantic change is warranted here, in connection with the reconstructed meanings of words presented above. One of the hazards of comparative reconstruction is the fact that the meanings of words change, often in response to social or technological changes. An example relevant to reconstructing the names of cereals can be seen in the author's reconstruction of the crops of the Southern Neolithic (Southworth 2009). Following are the four staple crops of the Southern Neolithic, as reconstructed linguistically and as identified archaeobotanically:

\begin{tabular}{|c|c|c|}
\hline $\begin{array}{l}\text { Dravidian } \\
\text { word }\end{array}$ & $\begin{array}{l}\text { Linguistic } \\
\text { reconstruction }\end{array}$ & $\begin{array}{l}\text { Archaeobotanical } \\
\text { identification }\end{array}$ \\
\hline *ko! & Horsegram & $\begin{array}{l}\text { Horsegram, Macrotyloma } \\
\text { uniflorum }\end{array}$ \\
\hline *pac-Vt/Vl & Mung & Mung, Vigna radiata \\
\hline *conna-l & Sorghum & Browntop millet, $B$. ramosa \\
\hline *kot-V & S. italica & $\begin{array}{l}\text { Bristley foxtail, } S . \\
\text { verticillata }\end{array}$ \\
\hline
\end{tabular}

While the two staple pulses, horsegram and mung, were correctly identified, the staple millets were both misidentified in the linguistic reconstruction. Sorghum and $S$. italica, it turns out, were introduced into the area some time later, and the names given to the earlier plants were transferred to the new ones-in the same way the English word pen, which originally meant "feather", was transferred ${ }^{8}$ to the successors of quill pens: the steel-nibbed pen, the fountain pen, the ballpoint pen, etc. In the case of the two millets, Fuller et al. (2009) pointed out that in both cases the newer plants were similar in appearance to those which they replaced (op cit); they also probably had similar agronomic characteristics and filled similar niches in people's food habits. While this explanation makes clear the reason for the misidentification, the fact remains that sometimes this is the best we can do. The more prudent course, as noted above, would be to opt for the most general definition, in this case "millet."

A different type of semantic change is exemplified by the English word corn, which is derived from the Germanic equivalent of Latin grānum and originally had many of the same meanings that we associate with the word grain (which came to us from Latin via Old French grain): note peppercorn, barleycorn, in which corn means "seed". When the American colonists came to know maize in America, they called it Indian corn, but after a few generations it came to be simply corn, as it is today, whereas in England the unmodified corn still refers to grain in general, as noted in the following excerpt from the Oxford English Dictionary's entry for corn:

Corn - in combinations, in American usage, must ... be understood to mean maize, whereas in English usage it may mean any cereal; e.g., a cornfield in England is a field of any cereal that is grown in the country, in U.S. one of maize.

In this case, semanticists would say that the meaning of the word corn was narrowed, or restricted, to a particular grain. The same type of change is exemplified by the history of the Proto-Peninsular Dravidian word *vari-(n)ci, which started out meaning "grain" or "seed", was later applied to barley, and subsequently to rice.

\footnotetext{
${ }^{8}$ Strictly speaking, such a transfer involves first an extension of meaning - the meaning of pen was extended to include the steel-nibbed pen as well as the quill pen - followed by a narrowing of meaning after the quill pen was no longer in use.
} 


\section{References}

Allchin FR. Neolithic cattle-keepers of South India: a study of the Deccan Ashmounds. Cambridge: Cambridge University Press; 1963.

Bellwood P. Early farmers: issues of spread and migration with respect to the Indian subcontinent. In: Osada $\mathrm{T}$, editor. Linguistics, archaeology and human past in South Asia. Delhi: Manohar; 2009. p. 55-70.

Blažek, V, Hegedus I. 2010. "On the position of Nuristani within IndoIranian", paper presented at the Sound of Indo-European 2 Conference in Opava, Czech Republic, November 2010.

Bradley D. Proto-Tibeto-Burman Grain Crops [This paper was presented at the Cornell Symposium. Reference is to the revised version.]

Burrow T, Emeneau MB. A Dravidian etymological dictionary, (abbr. DEDR). Revised ed. Oxford: Clarendon; 1984.

Fuller DQ. Silence before sedentism and the advent of cash-crops. In: Osada T, editor. Linguistics, archaeology and human past in South Asia. New Delhi: Manohar; 2009. p. 147-90. 169-173.

Krishnamurti B. The Dravidian languages. Cambridge: Cambridge University Press; 2003.

McAlpin DW. Proto-Elamo-Dravidian: the evidence and its implications. Philadelphia: The American Philosophical Society; 1981.

McAlpin DW. Velars, uvulars, and the North Dravidian hypothesis. J Am Orient Soc. 2003;123(3):521-46.
Nampoothiry MN. Indian toponymy. A critical evaluation of the work done in this field in India with a bibliography. In: Ramachandran P, Nachimuthu K, editors. Perspectives in place name studies: Proceedings of the National Seminar on South Indian Place Names, Held at Trivandrum on 21-23 June 1985. A Festschrift to Prof. V.I. Subramoniam, On His Sixtieth Birth Day. Trivandrum: Place Name Society; 1987. p. 1-47.

Parpola A. On the Asiatic wild asses and their vernacular names. In: Osada T, Endo H, editors. Occasional Paper 12: linguistics, archaeology and the human past. Kyoto: Indus Project, Research Institute for Humanity and Nature; 2011.

Southworth FC. Linguistic archaeology of South Asia. London: Routledge; 2005.

Southworth FC. New light on three South Asian language families. Mother Tongue. 2006;XI:124-59.

Southworth FC. Proto-Dravidian agriculture. In: Osada T, editor. Linguistics, archaeology and human past in South Asia. Manohar: New Delhi; 2009.

The Oxford English dictionary [electronic resource]: The original Oxford English dictionary on compact disc/software by International Computaprint Corp. Edition: Version 4.10. Fort Washington, Pa.: Tri Star Pub., c1987.

Turner RL. A comparative dictionary of the Indo-Aryan languages. London: Oxford University Press; 1966.

Witzel M. Substrate languages in Old Indo-Aryan. Electron J Vedic Stud. 1999;5:1-67. 